\title{
Editorial
}

\section{La Ingenieria Industrial presente y futuro}

La ingeniería, ha sido un motor importante del desarrollo industrial, social, cultural y político del país a través de la investigación, la transferencia de tecnología e innovación social, y viene siendo uno de los principales generadores del cambio que se sucede en las últimas décadas en nuestro país.

Esta importante participación al cambio que aporta la ingeniería, sin duda, se soporta en uno de sus pilares del conocimiento ingenieril, "la Ingeniería Industrial," que desde la revolución industrial y épocas posteriores se actualiza a los requerimientos que la industria de bienes y/o servicios reclama, para dar respuesta a las exigencias y necesidades del hombre.

Durante las épocas pasadas a la actual en las que la ingeniería industrial ha tenido tanta trascendencia y los cambios se dieron sucesivamente, es importante tener en cuenta los grandes aportes que con los principios éticamente fundamentados de administración, producción y recompensas dieron a la ingeniería industrial Frederick W. Taylor, Henri Fayol, Henry Ford (padre de las cadenas de producción moderna, utilizadas para la producción continua en serie), entre otros.

Los aportes y fundamentos que la ingeniería industrial ha utilizado, aplicado, adecuado y modernizado han sido influenciados por la globalización, el desarrollo tecnológico y la transferencia de conocimiento, que se da en su momento facilitada por las Tics, y que deben ser direccionados hacia un currículo de Ingeniería Industrial para dar respuesta a una sociedad como la nuestra en vía de desarrollo.

El Ingeniero Industrial debe actuar con amplios conocimientos de las nuevas tecnologías, siendo impulsor del desarrollo industrial, generando empleo y creando empresas que participen activamente en el mejoramiento y bienestar de la región y del país.

Los aportes y principios éticos dados por los padres de la ingeniería industrial desde sus inicios, así como los conocimientos recientes se actualizan, se modernizan y se aplican complementados por los requerimientos de la modernidad y facilitados por las comunicaciones.

Las instituciones formadoras de Ingenieros Industriales deben tener el compromiso de reflejar en su currículo las necesidades impuestas en el perfil profesional que la modernidad exige y responder a él, para que el futuro de la ingeniería industrial se encuentre alineada con las necesidades de la sociedad, haciendo de la empresa una organización sustentable no solo en lo económico, ambiental y social, sino éticamente responsables que le permitan abordar las exigencias propias del mundo, que reflexione sobre las actuaciones humanas, preocupándose por la paz, la justicia, el desarrollo sostenible, la innovación y la creatividad. 
La formación del ingeniero Industrial en consecuencia debe responder al desarrollo de competencias profesionales que hagan que el ingeniero industrial se desempeñe éticamente y profesionalmente comprometido como Ingeniero, administrador, asesor consultor, generador de empresas y como investigador.

El futuro de la ingeniería industrial dependerá de la capacidad de asimilación que tenga a los cambios que se suceden drástica y sucesivamente, así como a la facilidad de adecuación y aceptación al cambio que los ingenieros industriales puedan asimilar acorde a su formación, y al compromiso de las instituciones educativas involucradas para que respondan a las necesidades y exigencias de la época futura a la que se enfrenten.

La Ingeniería Industrial, es y será una ingeniería de actualidad con tejido social ético y permanente investigación, con misión y visión futurista. Esto marcará su futuro y permanencia.

Jorge Gutiérrez Cancino

Director Programa de Ingeniería Industrial Universidad de América 